\title{
A first-generation microsatellite-based genetic linkage map of the Siberian jay (Perisoreus infaustus): insights into avian genome evolution
}

\author{
Sonja Jaari, Meng-Hua Li* and Juha Merilä
}

Address: Ecological Genetics Research Unit, Department of Biological and Environmental Sciences, PO Box 65, FIN-00014 University of Helsinki, Finland

Email: Sonja Jaari - sonja.jaari@helsinki.fi; Meng-Hua Li* - menghua.li@helsinki.fi; Juha Merilä - juha.merila@helsinki.fi

* Corresponding author

Published: 3 January 2009

BMC Genomics 2009, 10:1 doi:10.1186/1471-2164-10-1
Received: 16 July 2008

Accepted: 3 January 2009

This article is available from: http://www.biomedcentral.com/147/-2164/10/I

(c) 2009 Jaari et al; licensee BioMed Central Ltd.

This is an Open Access article distributed under the terms of the Creative Commons Attribution License (http://creativecommons.org/licenses/by/2.0), which permits unrestricted use, distribution, and reproduction in any medium, provided the original work is properly cited.

\begin{abstract}
Background: Genomic resources for the majority of free-living vertebrates of ecological and evolutionary importance are scarce. Therefore, linkage maps with high-density genome coverage are needed for progress in genomics of wild species. The Siberian jay (Perisoreus infaustus; Corvidae) is a passerine bird which has been subject to lots of research in the areas of ecology and evolutionary biology. Knowledge of its genome structure and organization is required to advance our understanding of the genetic basis of ecologically important traits in this species, as well as to provide insights into avian genome evolution.

Results: We describe the first genetic linkage map of Siberian jay constructed using 117 microsatellites and a mapping pedigree of 349 animals representing five families from a natural population breeding in western Finland from the years 1975 to 2006. Markers were resolved into nine autosomal and a Z-chromosome-specific linkage group, 10 markers remaining unlinked. The best-position map with the most likely positions of all significantly linked loci had a total sex-average size of $862.8 \mathrm{cM}$, with an average interval distance of $9.69 \mathrm{cM}$. The female map covered $988.4 \mathrm{cM}$, whereas the male map covered only $774 \mathrm{cM}$. The Z-chromosome linkage group comprised six markers, three pseudoautosomal and three sex-specific loci, and spanned $10.6 \mathrm{cM}$ in females and $48.9 \mathrm{cM}$ in males. Eighty-one of the mapped loci could be ordered on a framework map with odds of $>1000: 1$ covering a total size of $809.6 \mathrm{cM}$ in females and $694.2 \mathrm{cM}$ in males. Significant sex specific distortions towards reduced male recombination rates were revealed in the entire best-position map as well as within two autosomal linkage groups. Comparative mapping between Siberian jay and chicken anchored 22 homologous loci on 6 different linkage groups corresponding to chicken chromosomes Gga I, 2, 3, 4, 5, and Z. Quite a few cases of intra-chromosomal rearrangements within the autosomes and three cases of inter-chromosomal rearrangement between the Siberian jay autosomal linkage groups (LGI, LG2 and LG3) and the chicken sex chromosome GgaZ were observed, suggesting a conserved synteny, but changes in marker order, within autosomes during about 100 million years of avian evolution.

Conclusion: The constructed linkage map represents a valuable resource for intraspecific genomics of Siberian jay, as well as for avian comparative genomic studies. Apart from providing novel insights into sex-specific recombination rates and patterns, the described maps - from a previously genomically uncharacterized superfamily (Corvidae) of passerine birds - provide new insights into avian genome evolution. In combination with high-resolution data on quantitative trait variability from the study population, they also provide a foundation for QTL-mapping studies.
\end{abstract}




\section{Background}

Under various completed or ongoing projects, rapid progress has been attained in the generation of genomic resources for model organisms and domestic animals of medical, economic, or agricultural importance (e.g. [1$3])$. However, genomic resources for the majority of freeliving vertebrates of ecological and evolutionary importance are still scarce. For instance, in wild birds, development of genomic resources are still in their infancy, and only few initial efforts in linkage mapping [4-8], estimation of the extent of linkage disequilibrium $[9,10]$, and syntenic comparison between related species [7,8,11-14] ] have been conducted. Hence, very limited information on the genome structure of wild bird species is available for further synthesis, as well as to study and characterize molecular underpinnings of phenotypic traits. Since wild passerine birds are important 'model' organisms in ecology and evolutionary biology, and in studies of life history evolution (e.g. [15]), behaviour (e.g. [16,17]) and evolutionary quantitative genetics in particular (e.g. [18-20]), knowledge of their genome structure and organization is vital to advance our understanding of the genetic basis of ecologically important traits [21].

Genetic maps constitute essential and powerful organizational tools for genomic research [22]. Among the most important applications of genetic maps in genomic analyses is in that they provide a platform to support studies utilizing or aiming to apply candidate gene approaches $[21,23]$, QTL mapping [24], comparative genomics [25], and genome annotation [26]. However, construction of genetic linkage maps for non-model organisms is complicated by several factors $[27,28]$. One of the major obstacles for the construction of linkage maps in passerine birds (but see [4]) is the scarcity of informative genetic markers. Among a variety of molecular makers previously employed in linkage mapping in different organisms, microsatellite markers have often proven most useful due to their hypervariability, fast evolutionary rates, codominance, wide distribution throughout the genomes, and the relative ease with which they can be developed and genotyped using the polymerase chain reaction (PCR; e.g. [29]). While genetic maps exist in one form or another for various species, it is worth noticing that the studies are so far generally limited to domestic animals or natural populations of wild species that can easily be bred in captivity, or where sufficiently large litter sizes are being produced in natural settings and are accessible to sampling to allow the establishment of the pedigree necessary for linkage analysis [9]. Unfortunately, the characteristics that make populations practical for linkage mapping [9] are found only among a small fraction of species studied by ecologist and evolutionary biologists. Linkage maps have now been constructed in four populations of non-model animals for which long-term individual-based datasets are available (see also: [8]), and where natural long-term pedigrees (rather than experimental breeding programmes) have been used to follow the co-segregation of marker alleles [28]. Two of these mapping populations are in ungulate species (soay sheep, Ovis aries [24]; red deer, Cervus elaphus [27]) and two are in passerine birds (great reed warbler, Acrocephalus arundinaceus [4,6,13]; collared flycatcher, Ficedula albicollis $[5,9,11])$.

The Siberian jay (Perisoreus infaustus) is a passerine bird which has been subject to considerable ecological and evolutionary research during the past decades. Studies in its breeding biology [30-33], mating system [34,35], foraging behaviour [36], reproductive success [37], parental care and dispersal pattern [38,39], family structure [40], phenotypic plasticity [41] and levels of inbreeding [42] have been conducted. Thus, these previous studies form an appropriate setting in an initiative to explore the integration of genomics with the domain of ecology and evolutionary biology [43], provided that at least some basic knowledge of the species' genome can be obtained. With an access to detailed pedigrees of a Siberian jay population monitored over 30 years $[40,42]$, as well as access to a novel set of polymorphic microsatellites developed for this species [44], construction of a linkage map is now realistic. In an evolutionary context, the chicken genome sequence [45] released recently facilitates genomic studies in other bird species by comparative genomic approaches $[13,25]$. Moreover, given the early divergence of avian lineages between passeriforms and galliforms $(\approx 100$ million years ago; [46]) and the high level of phylogenetic divergence between jays belonging to the Corvidae family and the other passerines for which linkage maps have been published (e.g. $[47,48]$ ), a linkage map of the Siberian jay may provide new insights into avian genome evolution, and thereby also to the extensive morphological, life historical and behavioural diversification within the order Passeriformes (see [47]).

The aim of this study was to develop a first-generation genetic linkage map for a wild population of Siberian jays on the basis of 117 microsatellites, including a novel set of 108 markers. To this end, a framework map was constructed to identify markers whose local relative orders were statistically well supported with an unambiguous location in the map. Since heterochiasmy has been observed in previous studies of many species (e.g. zebrafish [49]; and great reed warbler [4]), sex-specific variation in the recombination rate and the genetic map distance were also investigated. Furthermore, to provide a comparative perspective to address the evolution of genome organisation the extent of synteny and locus order conservation between Siberian jay and chicken was evaluated by a BLAST analysis against the chicken genome sequence. 


\section{Results}

\section{Characteristics of polymorphic microsatellites}

Of the 117 microsatellites scored, six loci (SJ009, SJ046, SJ048, SJ069, SJ083 and SJ108) were assigned to the Zchromosome by observation of complete cosegregation with sex and the observation of heterozygosity in some males but none of the females in the pedigrees. None of the markers examined appeared to be situated in W-chromosome since all the markers had alleles in the males. The number of informative meioses varied from 33 (SJ047) to 474 (CKL5) with an average of 284.63 informative meioses per locus. More details about levels of genetic variability $\left(H_{\mathrm{O}}, H_{\mathrm{E}}\right.$ and PIC) are shown in Additional File 1.

\section{Genetic linkage maps}

An overview of the linkage data is given in Figures 1, 2 and Table 1 depicting the best-position and framework linkage maps and their characteristics. Of the 117 microsatellites, 107 loci (91\%) were assembled into 9 autosomal linkage groups (LG1 - LG9) and one Z-chromosome linkage group (LGZ), and the other 10 polymorphic microsatellites (SJ002, SJ003, SJ005, SJ020, SJ030, SJ034, SJ118, MJG1, PER1 and LTML8) appeared to be unlinked to any other marker by two-point analysis with LOD scores $<3.0$. Of the ten unmapped markers, six had less than 60 informative meioses while four had more than 200 informative meioses. Of the nine autosomal LGs, seven comprised of six or more loci and the remaining three LGs each contained two or three loci, with an average of $c a .11$ microsatellites per LG. For the sex-average autosomal LGs in the best-position map (Figure 1), the meiotic lengths, evaluated as the distance between the outermost markers on each LG, ranged from $10.6 \mathrm{cM}$ (LG09) to $185.6 \mathrm{cM}$
(LG01) spanning in total $862.8 \mathrm{cM}$ of the Siberian jay genome. The average marker interval was $9.69 \mathrm{cM}$ calculated as the arithmetic mean of the map distances between adjacent markers (Table 1$)$. On the maps, 35.9\% (33/92) of the intervals between markers varied from 0 to $5 \mathrm{cM}$, $31.5 \%$ (29/92) ranged from 5 to $10 \mathrm{cM}$, and 20.7\% (19/ 92) from 10 to $20 \mathrm{cM}$, and $12 \%(11 / 92)$ were $>20 \mathrm{cM}$.

Sex-specific autosomal maps were also constructed (Figure 1). The sum of the length of all autosomal LGs was $774.0 \mathrm{cM}$ in males and $988.4 \mathrm{cM}$ in females, with an average intermarker spacing of $8.6 \mathrm{cM}$ and $12.1 \mathrm{cM}$, respectively. The male map comprises LGs ranging in length from $7.7 \mathrm{cM}$ to $171.1 \mathrm{cM}$ while the female map contains LGs with a length from $9.2 \mathrm{cM}$ to $229.2 \mathrm{cM}$ (Table 1 ). Out of the nine pairs of male and female LGs, seven were larger in the female map and two were larger in the male map. In total, the autosomal LGs were smaller in males as compared to females with a female-to-male map ratio of 1.28. The sex-average map was intermediate in length between sex-specific maps, and 1.12 times longer than the male map.

Framework markers, which could be ordered with LOD score of 3.0 or greater (indicating odds of 1000:1), are indicated in bold fonts in the best-position map (Figure 1). Of the total 107 mapped markers, 81 loci were significantly ordered in the framework map and most (16/24) of the remaining loci could be placed with significant support in either of two alternative intervals. When only the framework markers were considered, the total size of autosomal linkage groups was $692.1 \mathrm{cM}$ in the sex-average map, $649.4 \mathrm{cM}$ in the male map, and $799 \mathrm{cM}$ in the female

Table I: Characteristics of the best-position and framework maps for Siberian jay

\begin{tabular}{|c|c|c|c|c|c|c|c|c|c|c|c|c|}
\hline \multirow[t]{2}{*}{ LG } & \multicolumn{6}{|c|}{ Best-position map (cM) } & \multicolumn{6}{|c|}{ Framework map (cM) } \\
\hline & No. of loci & $\begin{array}{l}\text { Sex } \\
\text { average }\end{array}$ & q & $\sigma^{x}$ & $\begin{array}{l}\text { Average } \\
\text { inter- } \\
\text { marker } \\
\text { distance }^{a}\end{array}$ & $\begin{array}{l}\text { Ratio of } q / \\
\sigma^{\top} \text { maps }\end{array}$ & No. of loci & $\begin{array}{l}\text { Sex } \\
\text { average }\end{array}$ & q & $\sigma^{x}$ & $\begin{array}{l}\text { Average } \\
\text { inter- } \\
\text { marker } \\
\text { distance }^{a}\end{array}$ & $\begin{array}{l}\text { Ratio of } q / \\
\sigma^{\top} \text { maps }\end{array}$ \\
\hline LGI & 29 & 185.6 & 213.6 & 168.3 & 6.87 & 1.27 & 20 & 167.0 & 182.8 & 156.7 & 8.35 & 1.17 \\
\hline LG2 & 27 & 181.5 & 229.2 & 141.3 & 6.72 & 1.62 & 21 & 141.3 & 212.1 & 116.8 & 6.73 & 1.82 \\
\hline LG3 & 13 & 182.6 & 197.9 & 17I.1 & 16.6 & 1.16 & 10 & 170.2 & 175.5 & 171.3 & 17.02 & 1.02 \\
\hline LG4 & II & 98.2 & 110 & 86.7 & 9.82 & 1.27 & 9 & 76.0 & 88.3 & 63.8 & 8.44 & 1.38 \\
\hline LG5 & 8 & 85.2 & 92.9 & 82.1 & 12.17 & 1.13 & 7 & 83.9 & 93.4 & 78.4 & 11.99 & 1.19 \\
\hline LG6 & 6 & 78.2 & 98.9 & 65.4 & 15.64 & 1.51 & 3 & 14.4 & 15.5 & 13.2 & 4.80 & 1.17 \\
\hline LG7 & 3 & 26.4 & 24.3 & 32.3 & 13.2 & 0.75 & 2 & 14.2 & 9.8 & 22.4 & 7.10 & 0.44 \\
\hline LG8 & 2 & 14.5 & 9.2 & 19.1 & 15.5 & 0.48 & 2 & 14.5 & 9.2 & 19.1 & 7.25 & 0.48 \\
\hline LG9 & 2 & 10.6 & 12.4 & 7.7 & 10.6 & 1.61 & 2 & 10.6 & 12.4 & 7.7 & 5.30 & 1.61 \\
\hline $\mathrm{LGA}^{b}$ & 101 & 862.8 & 988.4 & 774 & 9.69 & 1.28 & 76 & 692.1 & 799 & 649.4 & 9.11 & 1.23 \\
\hline LGZ & 6 & 23.8 & 10.6 & 48.9 & 4.76 & 0.22 & 5 & 22.1 & 10.6 & 44.8 & 4.42 & 0.24 \\
\hline
\end{tabular}

O Female-specific linkage groups

$\sigma^{7}$ Male-specific linkage groups

$a$ The average inter-marker distance is based on the sex-average map

${ }^{b}$ total autosomal linkage groups 


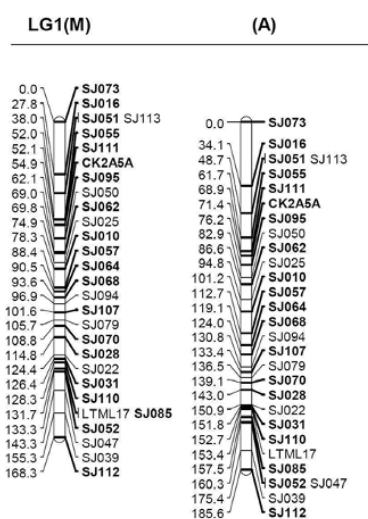

(F)

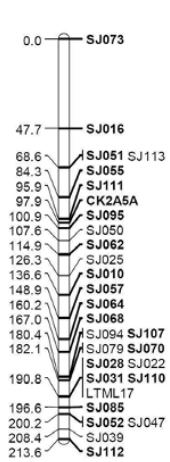

(A)

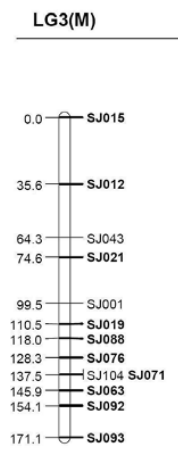

(F)

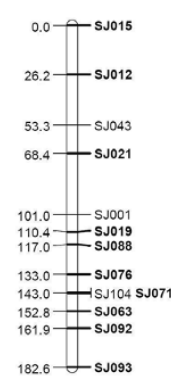

(A)

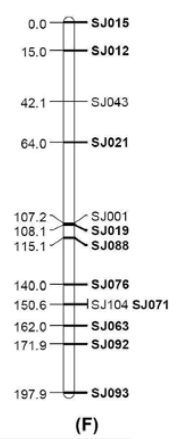

LG5(M)
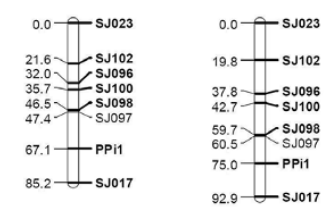

(A)

(F)

\begin{tabular}{|c|c|c|}
\hline $0.0-5 \mathrm{~s} 032$ & $0.0-\mathrm{SJ} 032$ & $0.0-5 \mathrm{SJ} 032$ \\
\hline${ }_{32.3}^{29.3} \alpha_{\mathrm{sJ117}}^{\mathrm{sJ}}$ & ${ }_{26.4}^{21.3} \mathcal{W}_{\mathbf{S J 1 1 7}}^{\mathbf{s} J 087}$ & $\begin{array}{l}\text { ssust } \\
\text { ssit }\end{array}$ \\
\hline 9 (M & (A) & \\
\hline
\end{tabular}

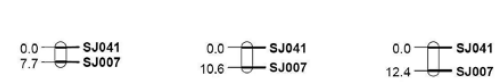

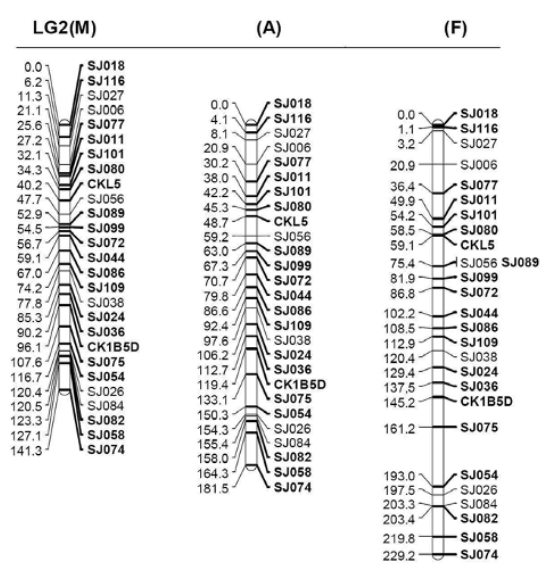

\begin{tabular}{lll}
$\mathrm{LG} 4(\mathrm{M})$ & (A) & (F) \\
\hline
\end{tabular}
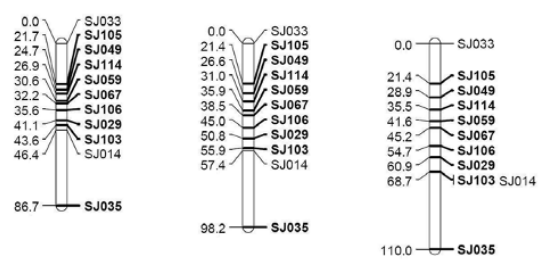

LG6(M)

(F)
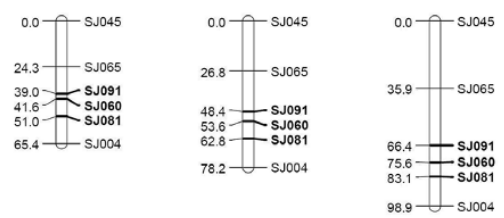

LG8(M)

(A) (F)

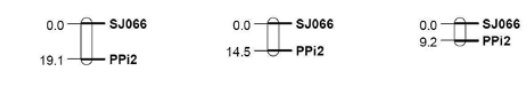

\begin{tabular}{lll}
$\operatorname{LGZ}(\mathrm{M})$ & (A) & (F) \\
\hline
\end{tabular}

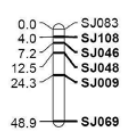

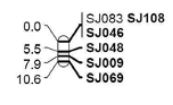

Figure I

The best-position linkage groups (male-specific, M; sex-average, A; and female-specific; F) in Kosambi centimorgans for the Siberian jay. The markers in boldface font are framework loci with unambiguous relative position between each other. 


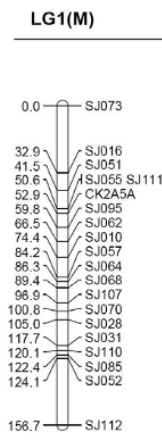

(A)
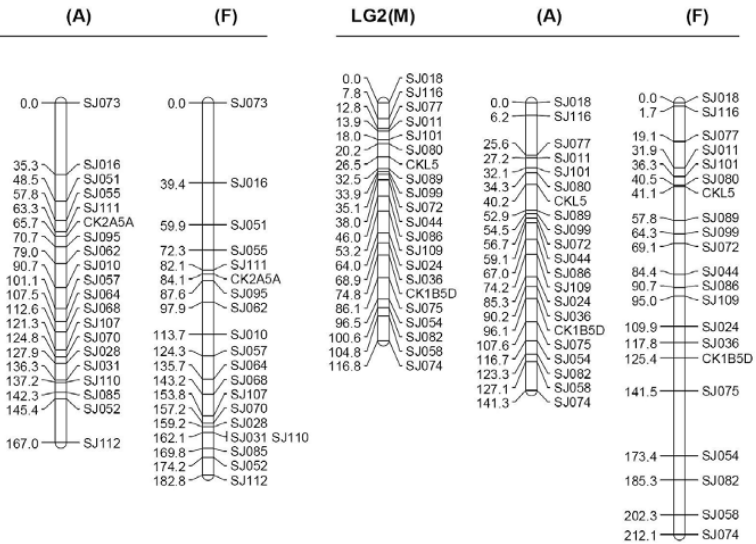

LG3(M)

(A)

(F)

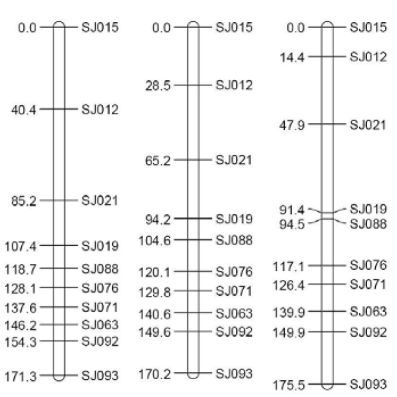

LG5(M)

(A)

(F)
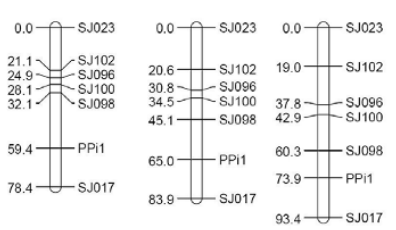

LG7(M)

(A)

(F)

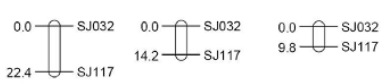

LG9(M)

(A)

(F)

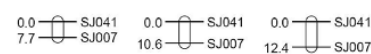

(F)

LG4(M) (A)

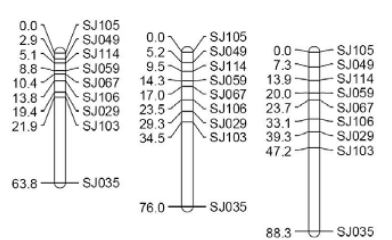

LG6(M)

(A) (F)

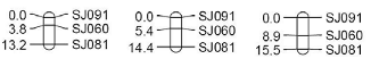

\begin{tabular}{lll}
$\mathrm{LG} 8(\mathrm{M})$ & $(\mathrm{A})$ & $(\mathrm{F})$ \\
\hline
\end{tabular}

${ }_{19.1}^{0.0} \int_{\mathrm{PPi} 2}^{\mathrm{SJ} 066}{ }_{14.5}^{0.0} \overbrace{\mathrm{PP} 12}^{\mathrm{SJ} 066}{ }^{0.0} \mathrm{f}_{\mathrm{PPi2}}^{\mathrm{SJ} 066}$

$\begin{array}{lll}\operatorname{LGZ}(\mathrm{M}) & \text { (A) } & \text { (F) }\end{array}$

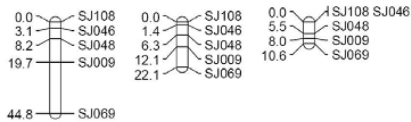

Figure 2

The framework linkage groups (male-specific, M; sex-average, A; and female-specific; F) in Kosambi centimorgans for the Siberian jay. 
map (Figure 2 and Table 1). We compared recombination distances between adjacent framework markers that were mapped on both the best-position map and the framework map and overall the female-to-male ratio for the framework map was 1.23 , slightly lower than the ratio of 1.28 observed above in the best-position map.

Among the Z-linked microsatellites, all six markers showed highly significant linkage between each other with LODs > 37.0. This linkage group spanned $23.8 \mathrm{cM}$ in the sex-average map, $48.9 \mathrm{cM}$ in the male map and 10.6 $\mathrm{cM}$ in female map, which corresponds to a female-to-male ratio of 0.22 . The female linkage map indicates the position and approximate extent of a pseudoautosomal region (PAR) from SJ069 to beyond SJ048. In females, no recombination was observed between SJ083 and SJ046 and no heterozygosity was observed for these markers; therefore they must lie outside the pseudoautosomal region, suggesting that the pseudoautosomal boundary lies between SJ048 and SJ046. As expected, there is considerable difference in male and female recombination rates for the pseudoautosomal region of the $\mathrm{Z}$-chromosome, with the male distance between SJ108 and SJ069 being $41.7 \mathrm{cM}$ as compared to the female distance of $5.1 \mathrm{cM}$. This increased sexspecific recombination rate between the three pseudoautosomal loci was similar to the observations in the pseudoautosomal regions of the mammalian sex chromosomes, for example in humans [50], ovines [51] and bovines [52]. In the sex-average map, the map density was $4.0 \mathrm{cM} /$ marker among all Z-linked markers and 3.3 $\mathrm{cM} /$ marker among the five framework loci.

\section{Differences in recombination rate between sexes}

In addition to a much shorter total length of autosomal linkage maps in males than in females, the maps allowed comparison of meiotic recombination rate between sexes. The sexes show significant differences in recombination rates, both in general and for specific pairs of linked markers (Wilcoxon's signed-rank test, $P=0.037$; Figure 3 and
Table 2). In the best-position map (Figure 1), the proportion of intervals in the autosomal linkage groups that demonstrated a higher recombination fraction in females was $54.3 \%$. Among all adjacent autosomal markers the recombination fraction was 1.28 times higher in females than in the males. However, there were exceptions to this in some LGs, and in some specific intervals within LGs. For instance, LG7 and LG8 exhibited higher recombination fractions in males than in females (Table 2). The number of intervals that show higher recombination fractions in the male map relative to the female map was less, but not negligible (Figure 3 ). When investigating the distortions over the autosomal linkage groups, two of the nine linkage groups showed significant $(P<0.05)$ difference in recombination rate between the sex-specific maps (Table 2). This was also observed when the overall map length was investigated for sex-specific difference. All in all, these results suggest that overall recombination is significantly suppressed in male meiosis as compared to female meiosis.

\section{Comparative mapping}

The BLAST searches under both settings generated the same set of significant hits at $1 \mathrm{e}^{-10}$. We found 25 homologous $(21.4 \%, 25 / 117)$ zebra finch sequences using a cross-species MEGABLAST search in NCBI's zebra finch genome database (Table 3 ). By BLAST searching using two methods, in total 22 mapped $(20.5 \%, 22 / 107)$ and three unlinked loci for which a homologous sequence could be identified in chicken were assigned to a chromosomal location in the chicken genome (Table 3). The 10 Siberian jay LGs corresponded to five different autosomal and one $\mathrm{Z}$ chromosome in chicken. Loci from the same Siberian jay LG matched sequences on a single chicken chromosome in the BLAST analysis (Figure 4 and Table 3 ), with the exception of loci SJ039, SJ101 and SJ076 on the autosomal LGs (LG1, LG2, and LG3, respectively) that mapped to chicken chromosome $\mathrm{Z}$ (GgaZ), whereas the other loci on these LGs mapped to the chicken autosomes.

Table 2: The Wilcoxon's signed-rank test results for recombination fraction $(\theta)$ between sexes with linkage groups

\begin{tabular}{llllll}
\hline Linkage groups & $N^{a}$ & Average $\theta_{\mathrm{F}}{ }^{b}$ & Average $\theta_{\mathrm{M}^{c}}$ & $\theta_{\mathrm{F}} / \theta_{\mathrm{M}}$ & Wilcoxon's signed-rank test $(P)^{d}$ \\
\hline LGI & 28 & 0.071 & 0.055 & 1.29 & 0.174 \\
LG2 & 26 & 0.085 & 0.054 & 1.57 & $0.046 *$ \\
LG3 & 12 & 0.152 & 0.133 & 1.14 & 0.323 \\
LG4 & 10 & 0.101 & 0.077 & 1.31 & $0.038 *$ \\
LG5 & 7 & 0.127 & 0.110 & 1.15 & 0.687 \\
LG6 & 5 & 0.178 & 0.126 & 1.41 & 0.192 \\
LG7 & 2 & 0.115 & 0.145 & 0.79 & 0.5 \\
LG8 & 1 & 0.09 & 0.18 & 0.5 & - \\
LG9 & 1 & 0.12 & 0.08 & 1.5 & - \\
Total autosomal & 92 & 0.101 & 0.079 & 1.28 & $0.037 *$ \\
LGZ & 5 & 0.02 & 0.094 & 0.21 & $0.025^{*}$ \\
\hline
\end{tabular}

${ }^{a}$ number of intervals; ${ }^{b}$ average recombination fraction in females; ${ }^{c}$ average recombination fractions in males; $d *$, significant, $P<0.05$. 


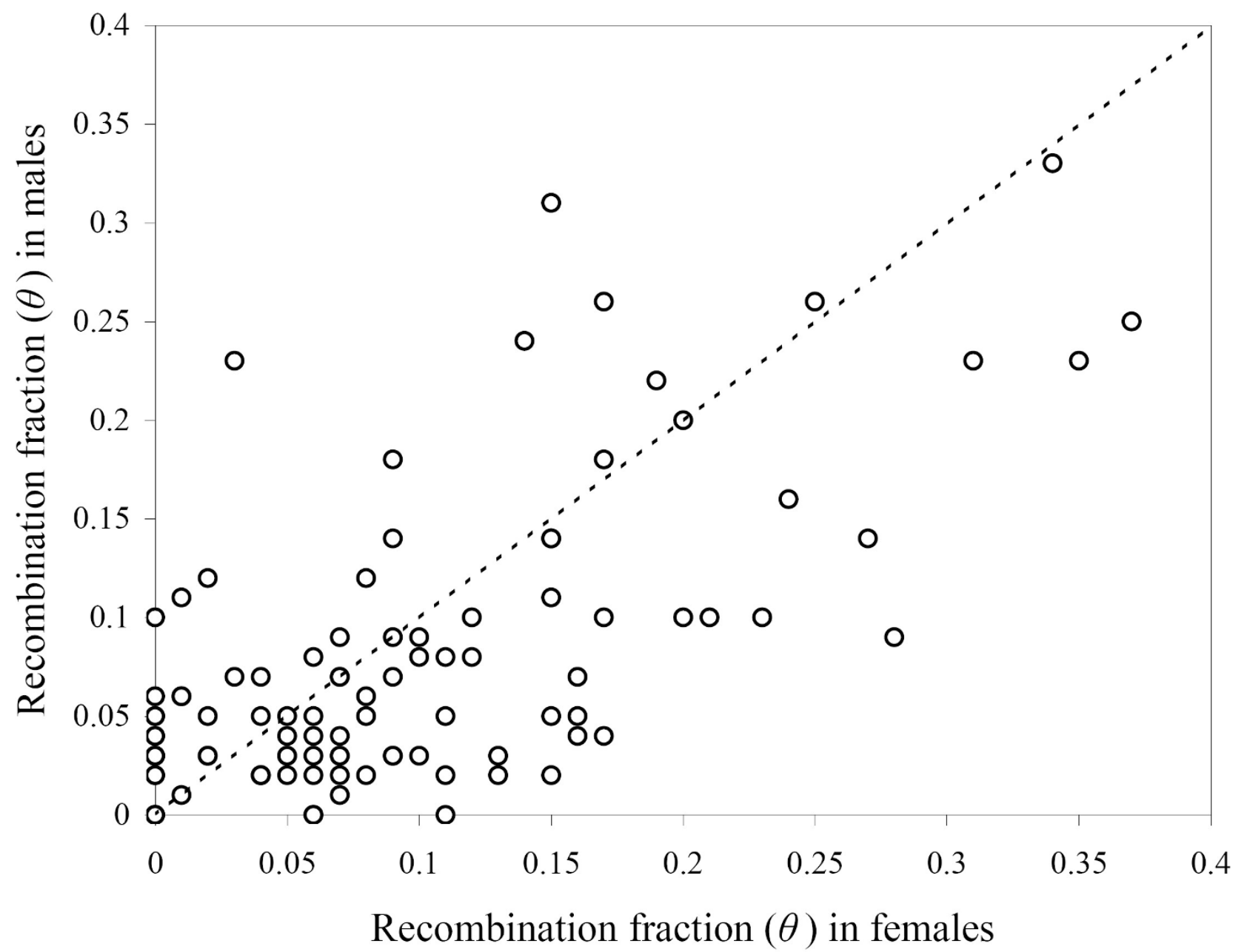

Figure 3

Female vs. male recombination fraction for 97 pairs of adjacent markers from the 10 linkage groups in the Siberian jay.

Likewise, most loci on the same chicken chromosome matched sequences on a single Siberian jay LG, with the exceptions of three unlinked loci (SJ005, SJ020 and SJ034) and loci SJ009, SJ039, SJ101 and SJ076 on GgaZ that mapped to four different LGs, LGZ and LG1, LG2, and LG3, respectively.

The relative order of the markers mapped to the Siberian jay LGs was compared with the same loci on chicken chromosomes in Figure 4. The chicken-Siberian jay comparison indicated that the order of loci was strikingly different between the chicken macrochromosomes Gga1, Gga2 and Siberian jay LG1, LG2 in the best-position map, respectively. Although some loci shared the same relative order in the two species, large rearrangements of the chromosome would have been necessary to give rise to the differ- ent orders found here. The cases of inter- and intrachromosomal rearrangements were involved mostly in the framework loci and represented a large proportion of Gga-LG1 that spanned around a 120-cM Siberian jay/20$\mathrm{Mb}$ chicken interval. The three unlinked loci, SJ005, SJ020, and SJ034, were located at the distal ends of two chicken macrochromosomes, Gga1 and Gga2.

\section{Discussion}

This study constitutes the first mapping effort of the Siberian jay genome, and is among the first ones to present a preliminary linkage map for any entirely natural vertebrate species from the wild (reviewed in [28]). The linkage map was composed using 107 polymorphic microsatellite loci typed on $c a$. 350 animals, making it one of the most detailed linkage maps available for natural animal popu- 
Table 3: The homologous loci of microsatellites mapped in Siberian jay on the chicken and zebra finch genome assigned using BLAST analyses of the clone sequences of the microsatellites and the homologous zebra finch WGS sequences.

\begin{tabular}{|c|c|c|c|c|c|}
\hline Locus & Linkage group & Zebra finch Ensemble ID & Chicken Ensemble ID & $\mathrm{Gga}^{a}$ & Chicken genome start position (bp) \\
\hline SJ0I0 & LGI & $\mathrm{gb} \mid \mathrm{ACI} 88472 . \mathrm{I}$ & NW_00I47I554.I Ggal_WGA5I_2b & 1 & $9,129,918$ \\
\hline SJ0I6 & LGI & - & NW_00I47I545.I Ggal_WGA43_2b & 1 & $9,256,107$ \\
\hline Sj022 & LGI & - & NW_00I47I526.I Ggal_WGA26_2b & 1 & $2,462,620$ \\
\hline Sj025 & LGI & $\mathrm{gb} \mid \mathrm{ACI} 88472 . \mathrm{I}$ & NW_00I47I534.I Ggal_WGA33_2b & I & $20,407,077$ \\
\hline Sj057 & LGI & - & NW_00I47I554.I Ggal_WGA5I_2b & 1 & $7,801,901$ \\
\hline Sj094 & LGI & - & NW_00I47I554.I Ggal_WGA5I_2b & 1 & $22,042,793$ \\
\hline SJII3 & LGI & - & NW_00I47I545.I Ggal_WGA43_2b & 1 & $8,757,200$ \\
\hline Sj020 & unlinked & - & NW_00I47I529.I Ggal_WGA29_2b & 1 & $1,098,266$ \\
\hline Sj005 & unlinked & $\mathrm{gb}|\mathrm{ACI} 88| 84.3$ & NW_00I47I5I3.I Ggal_WGAI4_2c & 1 & $2,080,202$ \\
\hline SJ036 & LG2 & - & NW_00147I639.1 Gga2_WGA66_2b & 2 & $20,469,429$ \\
\hline Sj072 & LG2 & - & NW_00I47I633.I Gga2_WGA60_2b & 2 & $32,273,874$ \\
\hline CK.IB5D & LG2 & $\mathrm{gb} \mid \mathrm{AC} 225878.2$ & NW_001471639.1 Gga2_WGA66_2b & 2 & $23,539,833$ \\
\hline SJ026 & LG2 & $\mathrm{gb|AC2} 206427.2$ & NW_00I47I639.1 Gga2_WGA66_2c & 2 & $21,465,630$ \\
\hline Sj054 & LG2 & gb|ACI88I86.2 & NW_00147I633.1 Gga2_WGA60_2c & 2 & $6,229,425$ \\
\hline SJII6 & LG2 & $\mathrm{gb}|\mathrm{ACI}| 48379.2$ & NW_00I47I633.I Gga2_WGA60_2c & 2 & $22,279,892$ \\
\hline Sj034 & unlinked & - & NW_00I47I654.I Gga2_WGA8I_2b & 2 & $2,075,856$ \\
\hline SJOI5 & LG3 & $\mathrm{gb}|\mathrm{ACl} 88| 88.2$ & NW_00147I673.I Gga3_WGAI06_2c & 3 & $3,458,567$ \\
\hline Sj032 & LG7 & - & NW_00I47|68I.I Gga4_WGA107_2b & 4 & $8,679,773$ \\
\hline Sj087 & LG7 & $\mathrm{gb} \mid \mathrm{ACI} 155211.2$ & NW_00147I68I.I Gga4_WGAI07_2c & 4 & $4,015,500$ \\
\hline SJII & LG7 & - & NW_00147I68I.I Gga4_WGA107_2b & 4 & $8,679,607$ \\
\hline Sj049 & LG4 & - & NW_00147I710.1 Gga5_WGAI36_2b & 5 & $9,3 \mid 4,084$ \\
\hline Sj009 & LGZ & - & NW_00I488876.I GgaZ_WGA457_2b & Z & $1,4 \mid 2,682$ \\
\hline SJIOI & LG2 & $\mathrm{gb} \mid \mathrm{AC} 213969.2$ & NW_00I488849.1 GgaZ_WGA430_2b & Z & $1,097,987$ \\
\hline Sj039 & LGI & $\mathrm{gb} \mid \mathrm{AC} 23 \mathrm{I} 254.2$ & NW_00I488882.I GgaZ_WGA463_2c & $\bar{Z}$ & $1,315,022$ \\
\hline Sj076 & LG3 & gb|ACI88376.I & NW_00I488862.I GgaZ_WGA443_2c & Z & 825,441 \\
\hline SJ050 & LGI & $\mathrm{gb}|\mathrm{AC}| 89030 . \mathrm{I}$ & - & - & - \\
\hline Sj05I & LGI & gb|ACI89030.I & - & - & - \\
\hline Sj055 & LGI & gb|ACI89030.I & - & - & - \\
\hline SJ064 & LGI & $\mathrm{gb} \mid \mathrm{AC} 206426.2$ & - & - & - \\
\hline SJII & LGI & $\mathrm{gb}|\mathrm{AC}| 92320.2$ & - & - & - \\
\hline CK.2A5A & LGI & gb|ACI 88469.1 & - & - & - \\
\hline Sj029 & LG4 & gb|ACI 88184.3 & - & - & - \\
\hline Sj033 & LG4 & gb|ACI 88469.1 & - & - & - \\
\hline SJ106 & LG4 & $\mathrm{gb}|\mathrm{AC}| 88 \mathrm{I} 84.3$ & - & - & - \\
\hline Sj0I7 & LG5 & gb|ACI 92320.2 & - & - & - \\
\hline Sj04I & LG9 & gb|AC2I 0531.1 & - & - & - \\
\hline SJ069 & LGZ & $\mathrm{gb}|\mathrm{AC}| 88466.2$ & - & - & - \\
\hline Sj083 & LGZ & gb|AC229626.2 & - & - & - \\
\hline
\end{tabular}

${ }^{a}$ Chicken chromosome number; $b$ Via the clone sequences of the Siberian jay microsatellites; $c$ Via the homologous zebra finch WGS sequences

lations [28]. In fact, it is one of only a few genetic linkage maps of wild bird species to date. Apart from the revealing evidence for sex differences in recombination rates, the constructed maps represent an excellent resource from which the markers may be selected for future mapping projects in this and related species, as well as for comparative genomic studies of genome organisation. In what follows, we will discuss the salient features of the constructed linkage maps in comparison to similar maps and results from earlier studies. In particular, we will pay attention to sex-specific differences in recombination rates, map coverage and some other issues deserving future attention.

\section{Genotyping in the mapping population}

The constructed map contains 107 microsatellites, of which 101 are autosomal, three Z-chromosome-specific and three pseudoautosomal loci (see below). The ideal set of molecular marker data for linkage mapping has no missing values, no genotyping errors and the markers segregate in the expected ratio for the specific type of population [53]. In practice, however, mapping data is compromised in all of these respects. However, as simulated and concluded in previous research [53], the effect of missing genotypes depends greatly on the sample size: the smaller the sample, the more severe the effects are likely to be. In comparison to published simulations, in 

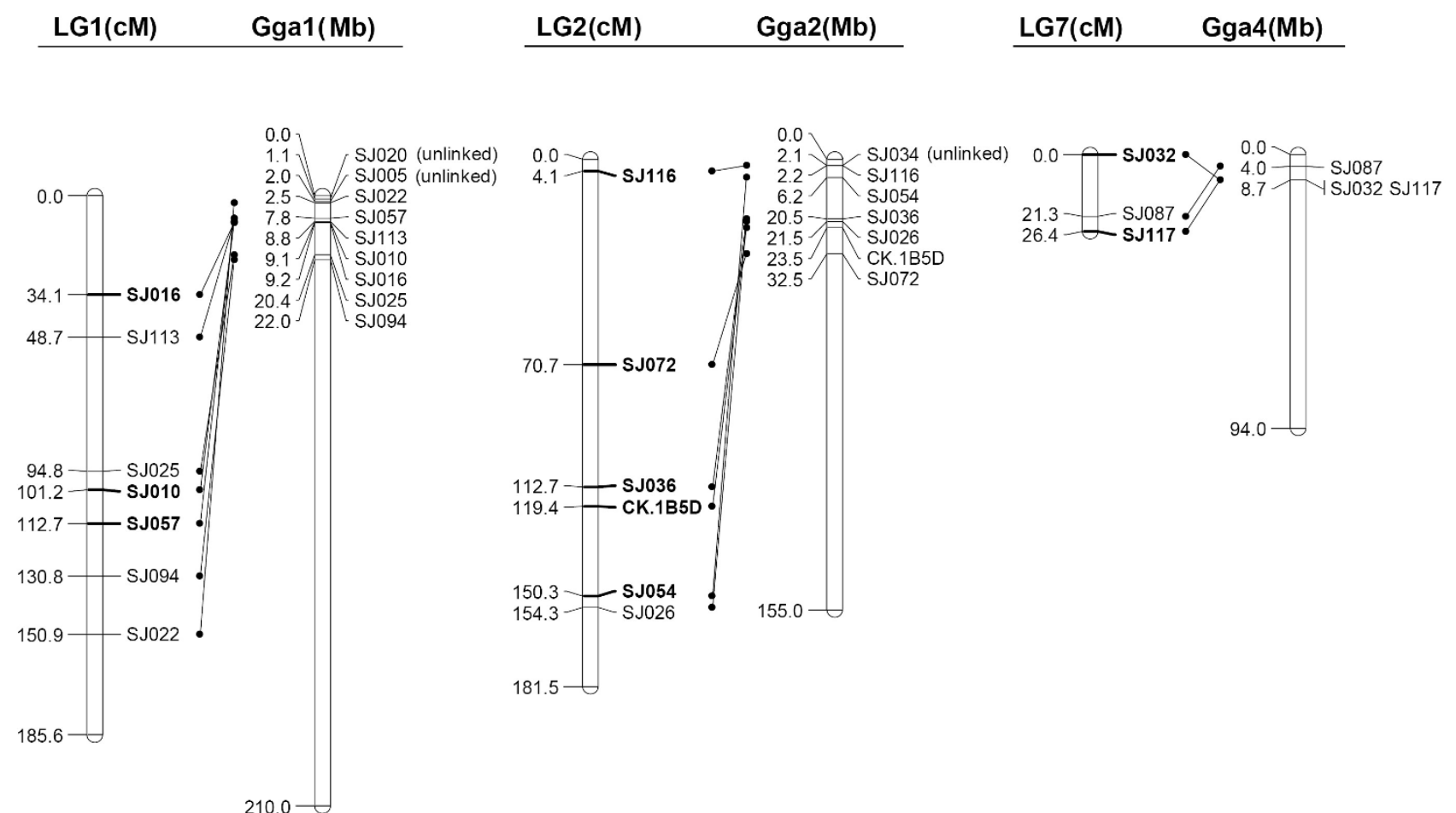

\section{LG3(cM) Gga3(Mb)}

\begin{tabular}{|c|c|c|c|}
\hline LG4(cM) & Gga5(Mb) & LGZ \& LG1, LG2, LG3 (cM) & GgaZ(Mb) \\
\hline
\end{tabular}
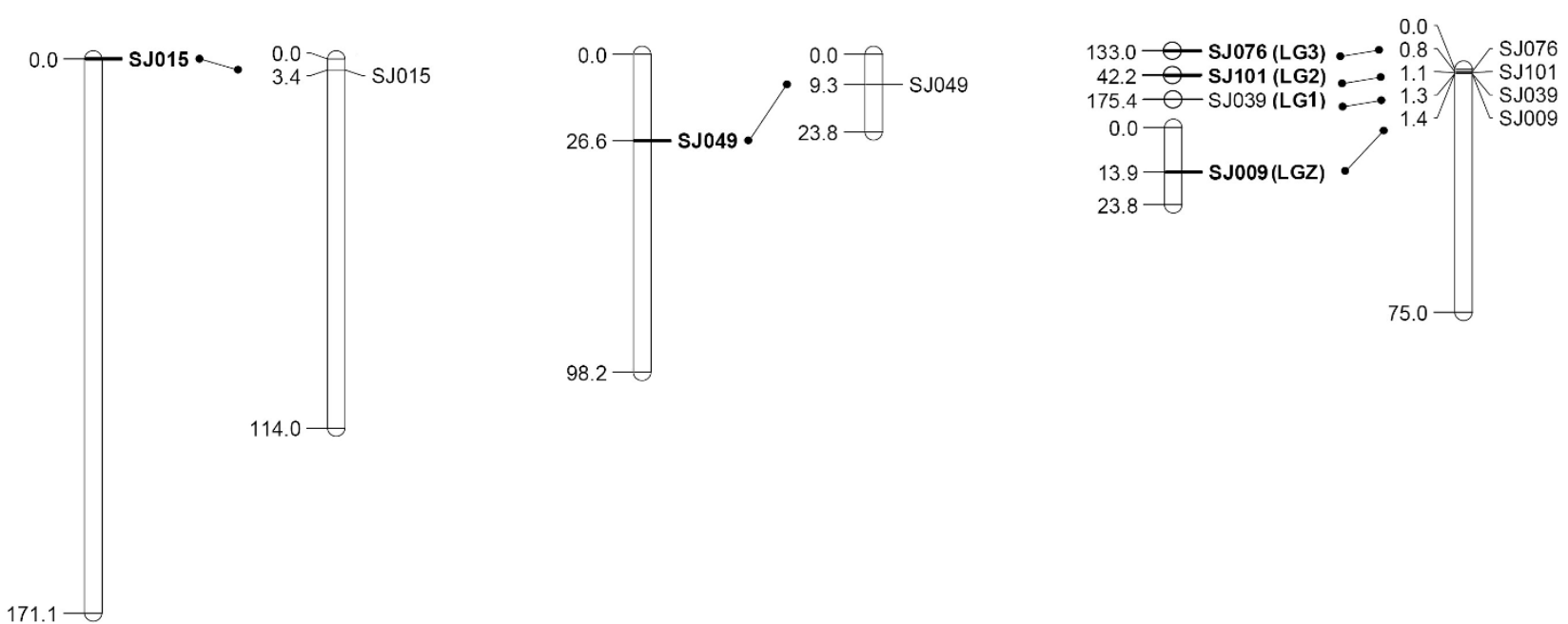

Figure 4

Comparison of the whole of all sex-average linkage groups in the Siberian jay and the whole of chicken chromosomes. The homologous loci on linkage groups and chromosomes are presented with their genetic positions (cM) on the best-position map or their genomic locations $(\mathrm{Mb})$ in the chicken genome. Siberian Jay marker names in bold font indicate framework loci. 
which the results were found to be quite robust with 150 individuals and $10 \%$ of missing values, our data had much less missing values (4.5\%) and a larger sample size (349 individuals). Hence, the potential biases in our map due to missing values are unlikely to be severe.

\section{Map construction and genome coverage}

The resulting linkage map of 107 microsatellites spans a total sex-average length of $886.6 \mathrm{cM}$, with 10 LGs. The number of markers within the data that showed significant linkage (LOD > 3.0) with at least one other marker was very high $(107 / 117,91.5 \%)$, a phenomenon observed also in a linkage mapping study of the great reed warbler [53]. Of the 10 unlinked markers (LOD < 3.0), four demonstrate sufficiently informative meiosis, suggesting that these four unlinked markers were most likely located on unique chromosomes or chromosome arms. The haploid number of $\mathrm{ca}$. 40 chromosomes is typical for passerine birds (e.g. 7 macro-, 32 micro-, and a pair of sexchromosomes in the zebra finch genome [54]) and the chicken genome is composed of 39 haploid chromosomes ( 8 macro and 30 micro, and a pair of sex chromosomes [54]). Thus, the presence of small groups and unlinked markers indicates that appreciable gaps of at least 29 additional linkage groups should be filled to consolidate the Siberian jay map. The discrepancy between the number of LGs and the haploid number of chromosomes has been commonly reported when constructing linkage maps in avian species (see [4]). These results could be explained in terms of the non-random distribution of microsatellites in the avian genome, where microchromosomes - typically scarce of microsatellites [55] - constitute a large proportion ( $\mathrm{ca} .80 \%$ ) of the total number of chromosomes.

Considering the avian order Passeriformes, the current sex-pooled map of the Siberian jay at $887 \mathrm{cM}$ is larger than recent maps in the great reed warbler $(155-237 \mathrm{cM}[4]$; $707-858 \mathrm{cM}[6])$, but smaller than those in the collared flycatcher $(1787 \mathrm{cM}[7])$ and the zebra finch $(1068 \mathrm{cM}$ [8]). The maximum genome coverage of the markers described in this study was estimated to be $1187 \mathrm{cM}(887$ $+200+100 \mathrm{cM})($ see $[56,57])$, covering about a third of the Siberian jay genome of $\sim 3800 \mathrm{cM}$, if estimated by assuming a similar genome size as in chicken [54]. It is clear that some of the microchromosomes are poorly represented, or not represented at all, in the current map. This poorer coverage of the microchromosomes, as well as of the Z-chromosome, is in good agreement with the observations in chicken [56], Japanese quail [58], duck [3], and great reed warbler $[4,6]$. However, it was argued in $[8]$ that for the whole-genome map of the zebra finch using 876 SNPs the shorter length of linkage map relative to that of the chicken is ascribed to its unusually lower recombination rates. Similarly, lower recombination rates and smaller length of linkage map were also revealed in the collared flycatchers based on 147 gene markers and 64 microsatellites [7]. Since it has been suggested that passerines generally have lower recombination rates than the chicken [8], the small map sizes here may also be partly due to reduced recombination rates in the Siberian jays. Nevertheless, the first-generation linkage map will undoubtedly evolve as more markers are added, with some additional linkage groups forming and some pairs of now described linkage groups coalescing into a single group. As linkage maps continue to develop, future work on the genetic map will increase the genome coverage by adding more novel genetic markers, for example, 1000's of SNP loci and additional markers will improve the resolving power of the map. A more saturated map should give more information about the genome size, exact karyotype number and chromosomal rearrangement of Siberian jay.

The constructed framework map was comprised only of loci with unambiguous positions relative to each other. As shown in Table 2, only a slight expansion of the framework map size was detected when the non-framework markers were included in the analysis. Non-significant $(P$ $>0.05$ ) difference in the interval distances between framework markers was found in the sex-specific maps when non-framework markers were included or not, which can be due to the fact that most (19/26) of the non-framework loci still can be placed with significant (LOD $=2$; odds of 100:1) support in either of two alternative intervals at LOD $=3$ (odds of 1000:1). However, on the sex-average maps, a significant $(P<0.05)$ difference in distances between framework markers was revealed when including or excluding the non-framework markers from the analysis. This is probably due to the overall effect of the recombination heterogeneity between the sexes on estimates of sex-average map distances between framework and nonframework markers [49]. Thus, our results indicate that the framework maps can serve as the backbone of the bestposition maps with a high level of confidence. Moreover, the framework map should also therefore provide a robust basis with which to apply to other pedigrees and for comparing genomic rearrangements with closely related species.

\section{Z-chromosome}

By assigning six genetic markers to the Z-chromosome on the basis of Mendelian inheritance and additional twopoint analysis tests, we found that the recombination rates in the Z-chromosome linkage group differed substantially among the sexes. In particular the ratio of recombination fraction in females $\left(\theta_{\mathrm{F}}\right)$ and males $\left(\theta_{\mathrm{M}}\right)$, $\theta_{\mathrm{F}} / \theta_{\mathrm{M}}$, in the LGZ $\left(\theta_{\mathrm{F}} / \theta_{\mathrm{M}}<1\right)$ contrasted markedly with those in seven of the nine autosomal linkage groups $\left(\theta_{\mathrm{F}}\right)$ $\left.\theta_{\mathrm{M}}>1\right)$. These results conform to the Z-chromosome link- 
age results from the chicken [56] and the great reed warbler $[4,6]$, suggesting significant sex-specific heterogeneity in recombination rate on the avian Z-chromosome. Between markers SJ046 and SJ069, a small amount of recombination (recombination fraction $\theta=0.02-0.05$ ) was found to occur between $\mathrm{Z}$ and $\mathrm{W}$ chromosomes in the mapping pedigree. $\mathrm{Z}-\mathrm{W}$ recombination has only once been previously reported in previous mapping efforts of birds based on SNPs (see [8]), but equivalent X-Y recombination has been observed in linkage mapping studies of sex chromosomes in many other species such as in salmonid fishes [59], rainbow trout [60], cattle [61], sheep $[51,62]$, oyster [63], and humans [64]. However, in contrast to increased recombination rates in heterogametic sex (male, XY) as observed in the pseudoautosomal regions of above mentioned studies, an overall 8-fold lower recombination rates between SJ048 and SJ069 were found in female (ZW) as compared to male (ZZ) Siberian jays. In addition, it seems as the pseudoautosomal region is extensive in Siberian jay $(15.8 \mathrm{cM} / 23.8 \mathrm{cM}, 66.4 \%)$. While in other species, $13.3 \%(20.1 \mathrm{cM} / 151 \mathrm{cM})$ were reported for the PAR in the bovine sex-average consensus map [52], $6.3 \%(3.5 \mathrm{cM} / 55.8 \mathrm{cM})$ in the male-specific and $45.1 \%(54.2 \mathrm{cM} / 121 \mathrm{cM})$ in the female-specific map of the sex chromosomes in sheep [51], and a very small proportion of PAR in the chicken sex chromosomal maps [56]. It is unclear why these are so, but potential explanations include the evolutionary strata [65], patterns of genome variability [66], distribution of sex-biased loci $[67,68]$, chiasma interference $[69]$ and selection $[70]$ on the avian Z-chromosome. Since the difference was found in the recombination rates and the change of genome structure during the avian evolution between Siberian jay and other wild bird species, we would like to speculate that the pattern of genome variability and distribution of sex-biased loci may have contributed more to this observation. Further investigations using more pseudoautosomal markers are needed to verify this result and understand its origin and significance.

\section{Recombination heterogeneity}

When testing for sex-specific differences in recombination rates in different linkage groups and over the total autosomal map, we found evidence for statistically significant distortions towards reduced male recombination fractions only in two autosomal LGs, rather than in each of the nine autosomal LGs. This indicates that the sex-related differences in recombination rates are confined to certain, specific parts of the genome. This result is not unexpected given that in many species there is a large variation in the recombination rates within and among chromosomes (see $[71,72])$. Similar situations of linkage group sex-specific distortion have also been observed in other species for example in marsupials (e.g. $[73,74])$ and in various aquatic organisms (the pacific oyster [63]; the tiger pufferfish [75]; and the turbot [76]).

Sex-specific differences in recombination rates have been found in a diverse range of organisms from molluscs (e.g. [77]) and fish (e.g. [49]) to mammals (e.g. pig [78]; cattle [79]; and human [80]). However, in birds various patterns have been reported: little evidence of heterochiasmy in chicken (Gallus domesticus, [54]) and zebra finch (Taeniopygia guttata [8]); higher rates of recombination in males than in females in linkage maps of blue tit (Parus caeruleus [81]) and collared flycatcher (Ficedula albicollis [7]); and higher rates of recombination in females than in males in maps of great tit (Parus major [81]), great reed warbler (Acrocephalus arundinaceus $[4,6]$ ) and house sparrow (Passer domesticus [14]). The sex-bias (females > males) observed in Siberian jay conforms to the last pattern opposing the Haldane's prediction [82] according to which the heterogametic sex should show lower recombination rates than the homogametic sex. So far the comparative data suggest a divergence between the genetic maps of the chicken (higher recombination rate and little difference in recombination rate between sexes) and the passerines (lower recombination rate and significant difference in recombination rate between sexes). Interestingly, on the one hand, we note the pronouncedly different patterns of recombination observed in collared flycatcher [11], zebra finch [8] and Siberian jay here, all of which are passerine birds. It has been proposed that heterochiasmy is the result of sexual selection, with the sex experiencing the greater variance in reproductive success exhibiting the lower recombination rate [83]. However, this explanation may not be relevant here because both collared flycatchers [84] and zebra finches [85] are polygamous, whereas the Siberian jay is a monogamous species $[34,37]$, so that the reproductive success should be very similar between the sexes. On the other hand, we found that the female:male recombination rate $(1.21)$ in the best-order map was much smaller than that observed in the great reed warbler where it varied from 2.15 (microsatellites[4]) to 1.86 (AFLP markers [6]). This difference is not necessarily biologically meaningful as it could be attributable to less informative and smaller number of loci (albeit larger number of individuals) in the earlier studies. Furthermore, since marker density in both Siberian jay and great reed warbler maps is relatively low and the sex-specific recombination rates heterogenous among and within linkage groups, the estimated female:male recombination rates among the maps may vary if different genomic regions are mapped

The observed sex-specific recombination rates are potentially influenced by numerous factors, and at the moment, there is no consensus in respect to the relative importance of mechanisms accounting for the recombination differ- 
ences (see $[63,73])$. For example, numbers of hypotheses including sexual selection [83]), haploid selection [86], sex differences in the internal or external environment [4] and sex differences in gene expression [67] have been evoked to explain the heterochiasmy pattern in birds. In this long-term isolated population studied here, we assume that the heterochiasmy could be more or less attributed to the sexual selection and the sex differences in the internal environment. However, irrespectively of the proximate mechanisms, the significant sex differences in recombination rates in the Siberian jay have obvious practical implications for future work. For instance, the lower average rate of recombination in males than in females should be advantageous for QTL-mapping of genetic traits in initial low resolution analysis [87].

\section{Conserved synteny, but changed marker order, in a genomic comparison with the chicken}

The study confirms the remarkable degree of conserved synteny between passerines and chicken (see [4,6$9,13,14]$ ), albeit based on only a small number of comparable chromosomes. Surprisingly, loci SJ039, SJ076 and SJ101 on autosomal LGs were mapped to GgaZ, which was known to be homologous to $\mathrm{Z}$ chromosome in passerines [this study, $[8,9,13]]$. As argued in [12], this observation may suggest chromosome fusions/fissions, a spurious match, or a more complex history of the loci. Future mapping studies may help to elucidate this. Locus SJ009, which was identified within the PAR region for the Siberian jay, was found to be conserved between LGZ and GgaZ. This is consistent with previous reports of cytogenetic and genetic mapping of the $Z$ chromosome that the PAR region was conserved between chicken and passerines $[8,88]$. However, this is not the case for the other three loci (SJ039, SJ076 and SJ101) on the autosomal LGs in Siberian jay. Thus, there are more inconsistencies than consistencies in the Z-chromosomal genomic comparison between Siberian jay and chicken in this study, which is different from previous results of Z-chromosomal synteny between the passerines and chicken $[9,12,13]$. Further studies to explore the potential explanations are needed in the future. The BLAST analysis located three unlinked loci, SJ005, SJ020 and SJ034 on Gga1 and Gga2. This can be explained by the fact that these three markers had few informative meioses and therefore low power in linkage analysis and/or that these loci are located in telomeric region, which may have a higher recombination rate. Indeed, as indicated in Figure 4, these three loci are located to the end of Gga1 and Gga2 in chicken (SJ005 at 2.0 Mb of Gga1, SJ020 at 1.1 Mb of Gga1; SJ034 at 2.1 Mb of Gga2).

Although synteny was conserved, there were multiple cases of inter- and intra-chromosomal rearrangements. Similar patterns have also been observed in other passer- ine birds on both sex and autosomal chromosomes (see $[9,14])$. As a contrast to the previous studies, the extent of chromosomal rearrangements as observed in the Gga1LG1 and Gga2-LG2 comparisons has not previously been reported. For example, in the comparative mapping analysis between the zebra finch and the chicken, only a few instances of inversions and translocations were found for chromosome 1 [8]. Of the total 22 homologous loci between chicken and Siberian jay found here, 12 loci (12/ $22,55 \%$ ) were involved in inter- or intra-chromosomal rearrangement, while a lesser proportion of the rearrangements were observed in the chicken/collared flycatcher (26/159, 16.4\%) [7] and chicken/great reed warbler (7/ $44,15.9 \%)$ comparisons [13]. There are several possible explanations for the different rates of genome evolution, e.g. the species-specific differences in rate of mutations and/or genome evolution could have contributed to the more or less genetic similarity of different passerines to the chicken; also, it has been suggested that population structuring in species with otherwise large population sizes facilitate chromosomal rearrangements. However, the scenario outlined here should be considered with caution because $(i)$ a small number of comparable chromosomes $(n=6)$ was identified here between the Siberian jay and the chicken; (ii) most of the chromosomal rearrangements are only from three chromosomes (chromosomes 1,2 and $Z$ ). Thus, further extensive comparative mapping of genomes and genetic linkage maps of the chicken, zebra finch, great reed warbler and Siberian jay with more and denser genome coverage should provide a more detailed picture of marker order rearrangement between passerines and chicken during avian evolution. Also, more sequence data to make the genome comparison between the chicken and the zebra finch, whose genomes are only currently sequenced in birds, is worthwhile. At any rate, the important message from our comparative analyses is that a high level of observed synteny does not necessarily mean conserved marker order. If the internal rearrangements tend to occur frequently across the genome, then map information derived from one species will not be readily transferable to another.

\section{Conclusion}

A salient feature of genetic linkage maps is that they improve with use. The described linkage maps of Siberian jay genome presented here, based on a large number of informative meioses, will serve as a basis for a future highresolution map. In particular, the framework map should enable the rapid construction of the next generation of higher-density linkage maps. From the evolutionary inference point-of-view, the linkage maps constructed here have potential to contribute to our understanding of patterns of genome evolution in birds, and that of passerines in particular. In addition, despite the need for increased density of markers, the maps will be also potentially use- 
ful for identifying QTLs and genomic regions related to traits of ecological importance. Furthermore, because the maps are constructed with codominant markers, they should be transportable to other pedigrees in this species, as perhaps also to closely related species where the microsatellites are conserved. Hence, the map will serve as a reference map for genomic analyses in the Siberian jay, as well as a useful resource for comparative genomic studies in birds. Last but not least, given the access to individual level fitness data from this pedigreed population, the map might prove useful for more detailed studies in genetics of fitness and inbreeding depression in this small isolate population [42].

\section{Methods}

\section{Study species and pedigree}

The Siberian jay (Perisoreus infaustus) is a medium sized (body mass ca. 85-90 g) and relatively long-lived (average generation time $c a .4$ years) oscine passerine bird from the Corvidae family $[89,90]$. It has a wide geographical distribution range in northern Eurasia where it occurs in the taiga forests from Fennoscandia to Siberia $[40,91]$. The Siberian jay has a stable socially monogamous breeding system and a prolonged brood care in which the dispersal of the young is delayed [34,37]. Hence, it lives in small territorial groups consisting of a breeding (alpha) pair, their retained offspring and/or unrelated immigrants $[34,39,92]$. Genetic diversity and structuring of the species has been investigated with mitochondrial DNA sequence analyses [91] and with a few available microsatellite markers [40,93]. However, its karyotype and genome structure remain undescribed. So far, $2 \mathrm{n}=80$ chromosomes is common in the order Passeriformes (e.g. $[13,88,94,95]$. Likewise, as in all avian species with heteromorphic sex chromosomes, the sex-determination in the Siberian jays conforms to the ZW female-ZZ male system [96].

The material for this study comes from a Siberian jay population breeding at Suupohja (ca. $66^{\circ} 18^{\prime} \mathrm{N}, 29^{\circ} 29^{\prime} \mathrm{E}$ ), western Finland. Annual individual-level monitoring of the population began in 1974 and has continued ever since. More details concerning the study population and field monitoring activities can be found from $[40,42,93,97]$. To obtain DNA, all animals used in this study were sampled for approximately $200 \mu \mathrm{l}$ of blood from the wing vein, or for tail feathers. Pedigrees for the population were established through direct field observation in combination with molecular parentage verification using microsatellite markers [40,93,97].

The mapping population analysed here was selected from a large Siberian jay data set comprising more than 1000 individuals. Five major families consisting of 349 animals (172 males and 177 females) from the years 1975 to 2006 were identified. In the total pedigree, 169 different male and 142 different female offspring were fathered by 85 males and mothered by 95 females. The five family pedigrees used for linkage analysis varied in depth from four to six generations and ranged in size from 72 to 97 animals. These family pedigree configurations yield large numbers of pairwise relationships, which include, but are not limited to, parent-offspring, full-sibs, half-sibs, grandparent-grandchild, great grandparent-great grandchild, avuncular, half-avuncular, and the first cousin relationships. The complex nature of the pedigree is mainly ascribed to two properties of the species. One is that the Siberian jays are philopatric, and some of the young remain in their natal territories up to the age of three years [98], such that the offspring occasionally enter the pedigree as parents in subsequent years. The other is that a few birds in one family are also involved as parental animals in another family and that several birds are present in more than one family pedigree. A more thorough description of the structure of the mapping pedigree can be found from $[40,42,93]$.

\section{Microsatellite markers and genotyping}

Genomic DNAs were extracted from blood samples or from the tail feather shafts using the DNeasy Blood \& Tissue Kit (Qiagen, Helsinki, Finland) following the manufacturer's instructions as described earlier in [44]. A total of 117 polymorphic microsatellite loci were used, including nine markers previously described in [93], 92 loci in [44] and 16 developed in this study. Development of the 16 new microsatellites reported in this study was carried out as described in [44] and sequence data from the loci have been deposited with EMBL/GenBank Data Libraries (see Additional File 1). Detailed information of all these loci including their names, primer sequences, Genbank accession numbers, repeat motifs and the size range of the detected alleles is available in Additional File 1. All PCRs were multiplexed by combining $3-4$ primer pairs in each reaction. The amplifications were performed in $10 \mu \mathrm{l}$ reactions with $2 \mathrm{pm}$ of each primer, $1 \times$ Quiagen multiplex mastermix, $0.5 \times$ Q-solution, and approximately $30 \mathrm{ng}$ of template DNA. The general temperature profile was 15 min at $95^{\circ} \mathrm{C}, 30$ cycles of $30 \mathrm{sec}$ at $94^{\circ} \mathrm{C}, 90 \mathrm{sec}$ at $56^{\circ} \mathrm{C}$ and $60 \mathrm{sec}$ at $72^{\circ} \mathrm{C}$, followed by a final extension step at $72^{\circ} \mathrm{C}$ for $10 \mathrm{~min}$. PCR products were analysed on MegaBACE $^{\text {TM }} 1000$ capillary sequencer (GE Healthcare Life Sciences, Little Chalfont, UK) and genotypes were determined using program Fragment Profiler version 1.2 (GE Healthcare Life Sciences, Little Chalfont, UK). In addition to the studied samples, one negative control and a reference DNA were included in all the amplifications in order to exclude the contaminant in the solutions and standardize the size of allele fragments of samples from different plates, respectively. 


\section{Genotype cleaning}

Identification and elimination of genotyping errors is a critically important task in genome mapping projects (see [53]). Several strategies have been applied to identify and eliminate any latent genotyping errors in this study. Initially, all individual genotypes were checked manually before export to Microsoft Excel worksheets. In addition, genotypes were analysed for Mendelian inheritance in the known pedigree using the "PREPARE" option in CRIMAP program version 2.4 [99] and incompatible genotypes were blanked. These blanks were either refilled with the correct genotypes after rechecking within Fragment Profiler or after running new PCRs where necessary. If these 'refill's did not work out, genotypes were scored as missing. In some cases, genotypes that were consistent with the Mendelian segregation, but highly improbable due to low relative allele frequencies in the pedigree, were also eliminated. Moreover, after preliminary alignment, the CHROMPIC option of the CRIMAP was used to identify unlikely double crossovers. Data contributing to double crossovers were re-examined and, if suspect, regenerated for second analysis. The overall genotype call rate was 95.5\% and when possible, missing data (mostly due to missing DNA samples) were inferred from the genotypes of parents/offspring.

\section{Linkage analysis and microsatellite characterization}

Genetic linkage maps were constructed using the program CRIMAP version 2.4 [99]. In the analyses, autosomal and Z-linked loci were evaluated separately. First, the TWOPOINT option of CRIMAP was used to obtain an estimated recombination fraction and a logarithm of the odds (LOD) score for every pair of markers. A widely used two-point LOD score threshold of three was set as a criterion for significant linkage and was used for configuration of a linkage group. Then linked markers were ordered within group following a procedure similar to that employed in [6]. For multipoint analysis of larger linkage groups we used the option BUILD to select loci to be used as a framework for the continuing ordering of them, beginning with the most informative pair of markers and positioning additional markers one at a time in order of decreasing informativeness; the order of selected markers, also called framework loci, was supported by a LOD score of three or higher. The remaining markers were added to the framework map by lowering the LOD threshold value to 2.0 or 1.0 and were represented as accessory markers in their most likely or best position. Finally, the options FLIPS $n$ and FIXED were used to evaluate the statistical support of the proposed order and the distance between markers, respectively. With the FLIPS $n(n=3-6)$ option, it is ensured that the odds in favour of the final order of each set of three to six markers were at least 1000:1 over alternative orders. Sex-average and sex-specific linkage genetic distances were estimated for each linkage group.
Relative mapping distance was further tested within group using the FIXED option. All map distances are expressed as Kosambi centiMorgans (cM).

The measures of microsatellite variability, including the observed number of alleles $\left(A_{\mathrm{E}}\right)$, observed heterozygosity $\left(H_{\mathrm{O}}\right)$, Nei's [100] unbiased estimates of expected heterozygosity $\left(H_{\mathrm{E}}\right)$ and polymorphic information content (PIC), were estimated with the Excel Microsatellite Toolkit $3.1[101]$.

\section{Comparative analysis}

Comparisons of clone sequences of the microsatellites in Siberian jay with the chicken genome sequence http:// www.ncbi.nlm.nih.gov/genome/guide/chicken/ were conducted using MEGABLAST http:www.ncbi.nlm.nih.go $\mathrm{v} /$ genome/seq/BlastGen/BlastGen.cgi?taxid=9031. The orthologous zebra finch sequence was identified by performing another cross-species MEGABLAST search in NCBI's zebra finch genome resource http:// www.ncbi.nlm.nih.gov/projects/genome/seq/BlastGen/ BlastGen.cgi?taxid=59729. Further, the homologous zebra finch sequences identified above (including their flanks) were matched against the chicken genome assembly using the same method as the BLAST analysis between the microsatellites in Siberian jay and the chicken genome sequence. The searches were performed following a procedure as detailed in $[7,12,13]$. At the Expect value $E=1 e^{-5}$, initial searches were performed under the default setting and later searches were under a less stringent set of parameters (the so called 'the relaxed setting' in [12]). A locus was assigned to a specific location in the chicken genome if (i) it provided a unique hit at $\mathrm{E} \leq 1 \mathrm{e}^{-10}$, or (ii) it provided multiple hits at $\mathrm{E} \leq 1 \mathrm{e}^{-10}$ and within the hits the best hit had an E value at least 10 decimal places lower than the next best hit (see [12]). All the graphic maps were generated using MapChart version 2.2 [102].

\section{Authors' contributions}

SJ designed the study, conducted the laboratory work and prepared the data. MHL inspected the data, performed the data analysis and wrote the manuscript. JM planned and coordinated the whole study, and contributed to the manuscript writing. All authors read and approved the final manuscript. 


\section{Additional material}

\section{Additional file 1}

Summary information on the Siberian jay microsatellites genotyped in this study. Excel worksheet containing locus name, genbank accession number, primer sequences, allele size range, position and interval distance on linkage group, number of alleles, observed and expected heterozygosity, polymorphic information content, and references.

Click here for file

[http://www.biomedcentral.com/content/supplementary/14712164-10-1-S1.xls]

\section{Acknowledgements}

This work was supported by grants from Academy of Finland and in particular through the funding to the Centre of Excellence in Evolutionary Genetics and Physiology. We thank Bo-Göran Lillandt for his invaluable efforts in the long-term field data collection and access to the DNA samples. Thanks are also due to all individuals and funding bodies which have - directly or indirectly - contributed to collection of the data. We are grateful to Kaisa Välimäki for her help in the molecular data preparation and Marika Karjalainen for technical assistance in laboratory. Craig Primmer, Jon Slate and John Loehr kindly commented on an earlier version of this paper.

\section{References}

I. Bishop MD, Kappes SM, Keele JW, Stone RT, Sunden SLF, Hawkins GA, Toldo SS, Fries R, Grosz MD, Yoo J, Beattie CW: A genetic linkage map for cattle. Genetics 1994, 136:619-639.

2. Rhodes M, Straw R, Fernando S, Evans A, Lacey T, Dearlove A, Greystrong J, Walker J, Watson P, Weston P, Kelly M, Taylor D, Gibson K, Mundy C, Bourgade F, Poirier C, Simon D, Brunialti AL, Montagutelli X, Gu'enet JL, Haynes A, Brown SD: A high-resolution microsatellite map of the mouse genome. Genome Research 1998, 8:531-542.

3. Huang Y, Zhao Y, Haley CS, Hu S, Hao J, Wu C, Li N: A genetic and cytogenetic map for the duck (Anas platyrhynchos). Genetic 2006, I 73:287-296.

4. Hansson B, Akesson M, Slate J, Pemberton JM: Linkage mapping reveals sex-dimorphic map distances in a passerine bird. Proceedings of the Royal Society B: Biological Sciences 2005, 272:2289-2298.

5. Backström N, Qvarnström A, Gustafsson L, Ellegren H: Levels of linkage disequilibrium in a wild bird population. Biology Letters 2006, 2:435-438.

6. Akesson M, Hansson B, Hasselquist D, Bensch S: Linkage mapping of AFLP markers in a wild population of great reed warblers: importance of heterozygosity and number of genotyped individuals. Molecular Ecology 2007, 16:2189-2202.

7. Backström N, Karaiskou N, Leder EH, Gustafsson L, Primmer CR, Qvarnström A, Ellegren $\mathrm{H}$ : A gene-based genetic linkage map of the collared flycatcher (Ficedula albicollis) reveals extensive synteny and gene order conservation during 100 million years of avian evolution. Genetics 2008, 179(3): 1479-1495.

8. Stapley J, Birkhead TR, Burke T, Slate J: A linkage map of the zebra finch Taeniopygia guttata provides new insights into avian genome evolution. Genetics 2008, 179:65I-667.

9. Backström N, Brandström M, Gustafsson L, Qvarnström A, Cheng H, Ellegren $\mathrm{H}$ : Genetic mapping in a natural population of collared flycatchers (Ficedula albicollis): conserved synteny but gene order rearrangements on the Avian Z Chromosome. Genetics 2006, 174:377-386.

10. Edwards SV, Dillon M: Hitchhiking and recombination in birds: evidence from MHC-linked and unlinked loci in red-winged blackbirds (Agelaius phoeniceus). Genetical Research 2004, 84:175-192.

II. Backström N, Fagerberg S, Ellegren H: Genomics of natural bird population: a gene-based set of reference markers evenly spread across the avian genome. Molecular Ecology 2008, 17:964-980.
12. Dawson DA, Burke T, Hansson B, Pandhal J, Hale MC, Hinten GN, Slate J: A predicted microsatellite map of the passerine genome based on chicken-passerine sequence similarity. Molecular Ecology 2006, I 5: 1299-1320.

13. Dawson DA, Akesson M, Burke T, Pemberton JM, Slate J, Hansson B: Gene order and recombination rate in homologous chromosome regions of the chicken and a passerine bird. Molecular Biology and Evolution 2007, 24:1537-1552.

14. Hale MC, Jensen H, Birkhead TR, Burke T, Slate J: A comparison of synteny and gene order on the homologue of chicken chromosome 7 between two passerine species and between passerines and chicken. Cytogenetic and Genome Research 2008, I 21:120-129.

15. Gustafsson L, Sutherland WJ: The costs of reproduction in the collared flycatcher Ficedula albicollis. Nature 1988, 335:8|3-8|5.

16. Komdeur J: Importance of habitat saturation and territory quality for evolution of cooperative breeding in the Seychelles warbler. Nature 1992, 358:493-495.

17. van Oers K, de Jong G, van Noordwijk AJ, Kempenaers B, Drent PJ: Contribution of genetics to the study of animal personalities: a review of case studies. Behaviour 2005, 142: I 185-1206.

18. Merilä J, Sheldon BC: Avian quantitative genetics. Current Ornithology 200I, 16: 179-255.

19. Merilä J, Kruuk LE, Sheldon BC: Cryptic evolution in a wild bird population. Nature 200I, 4I 2:76-79.

20. Nussey DH, Postma E, Gienapp P, Visser ME: Selection on heritable phenotypic plasticity in a wild bird population. Science 2005, 31 0:304-306.

21. Ellegren $\mathrm{H}$, Sheldon $\mathrm{BC}$ : Genetic basis of fitness differences in natural populations. Nature 2008, 452:169-175.

22. Sewell MM, Sherman BK, Neale DB: A consensus map for loblolly pine (Pinus taeda L.). I. Construction and integration of individual linkage maps from two outbred three-generation pedigrees. Genetics 1999, 151:321-330.

23. Falque M, Décousset L, Dervins D, Jacob AM, Joets J, Martinant JP, Raffoux X, Ribière N, Ridel C, Samson D, Charcosset A, Murigneux A: Linkage mapping of I454 new maize candidate gene loci. Genetics 2005, I 70:1957-1966.

24. Beraldi D, McRae AF, Gratten J, Slate J, Visscher PM, Pemberton JM: Development of a linkage map and mapping of phenotypic polymorphisms in a free-living population of soay sheep (Ovis aries). Genetics 2006, I73:1521-1537.

25. Ellegren $\mathrm{H}$ : The avian genome uncovered. Trends in Ecology \& Evolution 2005, 20: 180-186.

26. Eyras E, Reymond A, Castelo R, Bye JM, Camara F, Flicek P, Huckle Ej, Parra G, Shteynberg DD, Wyss C, Rogers J, Antonarakis SE, Birney $E$, Guigo R, Brent MR: Gene finding in the chicken genome. $B M C$ Bioinformatics 2005, 6:131.

27. Slate J, Visscher PM, MacGregor S, Stevens D, Tate ML, Pemberton JM: A genome scan for quantitative trait loci in a wild population of red deer (Cervus elaphus). Genetics 2002, 162:1863-1873.

28. Slate J: Robustness of linkage maps in natural populations: a simulation study. Proceedings of the Royal Society B: Biological Sciences 2008, 275:695-702

29. Goldstein DB, Schlötterer C: Microsatellites: Evolution and Applications. Oxford: Oxford University Press; 1999.

30. Blomgren A: Studies of less familiar birds, 162: Siberian jay. British Birds 197|, 64:25-28.

31. Lindgren F: lakttagelser rörande lavskrikan (Perisoreus infaustus) huvudsakligen dess häckningsbiologi. Fauna och Flora 1975, 70:198-210.

32. Kokhanov VD: Ecology of the Siberian jay in the Murmansk region. In Ekologiya i morfologiya ptits na kraynem severozapade SSSR Edited by: Zabrodin VA. Moscow: N; 1982:124-137.

33. Matero J: Breeding biology of the Siberian jay in Kuusamo. Aureola 1996, 21:74-87.

34. Ekman J, Sklepkovych B, Tegelström H: Offspring retention in the Siberian jay (Perisoreus infaustus): the prolonged brood care hypothesis. Behavioral Ecology 1994, 5:245-253.

35. Edenius L, Meyer C: Activity budgets and microhabitat use in the Siberian jay Perisoreus infaustus in managed and unmanaged forest. Ornis Fennica 2002, 79:26-33.

36. Sklepkovych B: The influence of kinship on foraging competition in Siberian jays. Behavioral Ecology and Sociobiology 1997, 40:287-296. 
37. Ekman J, Bylin A, Tegeström H: Increased lifetime reproductive success for Siberian jay (Perisoreus infaustus) males with delayed dispersal. Proceedings of the Royal Society B: Biological Sciences 1999, 266:9|I-9|5.

38. Ekman J, Baglione V, Eggers S, Griesser M: Delayed dispersal: living under the region of nepotistic parents. Auk 200 I, I I 8: I-I0.

39. Griesser M, Ekman J: Nepotistic alarm calling in Siberian jay, Perisoreus infaustus. Animal Behaviour 2004, 67:933-939.

40. Lillandt BG, Bensch S, von Schantz T: Family structure in the Siberian jay as revealed by microsatellite analyses. Condor 2003, 105:505-5I4.

41. Eggers S, Griesser M, Ekman J: Predator-induced plasticity in nest visitation rates in the Siberian jay (Perisoreus infaustus). Behavioral Biology 2004, 16:309-315.

42. Alho JS, Lillandt BG, Jaari S, Merilä J: Multilocus heterozygosity and inbreeding in the Siberian jay. Conservation Genetics 2009.

43. Feder M, Mitchell-Olds T: Evolutionary and ecological functional genomics. Nature Reviews Genetics 2003, 4:65I-657.

44. Jaari S, Välimäki K, Merilä J: Isolation and characterization of $\mathbf{1 0 0}$ microsatellite primers for the Siberian jay (Perisoreus infaustus). Molecular Ecology Resources 2008, 8:1469-1474.

45. International Chicken Genome Sequencing Consortium: Sequencing and comparative analysis of the chicken genome provide unique perspectives on vertebrate evolution. Nature 2004, 432:695-7।6.

46. van Tuinen M, Sibley CG, Hedges SB: The early history of modern birds inferred from DNA sequences of nuclear and mitochondrial ribosomal genes. Molecular Biology and Evolution 2000, 17:45I-457.

47. Barker FK, Barrowclough GF, Groth JG: A phylogenetic hypothesis for passerine birds: taxonomic and biogeographic implications of an analysis of nuclear DNA sequence data. Proceedings of the Royal Society B: Biological Sciences 2002, 269:295-308.

48. Treplin S: Inference of phylogenetic relationships in passerine birds (Aves: Passeriformes) using new molecular markers. In PhD thesis The University of Potsdam; 2006.

49. Singer A, Perlman H, Yan Y, Walker C, Corley-Smith G, Brandhorst $B$, Postlethwait J: Sex-specific recombination rates in zebrafish (Danio rerio). Genetics 2002, 160:649-657.

50. Schmitt K, Lazzeroni LC, Foote S, Vollrath D, Fisher EM, Goradia TM, Lange K, Page DC, Arnheim N: Multipoint linkage map of the human pseudoautosomal region based on single-sperm typing: do double crossovers occur during male meiosis? American Journal of Human Genetics 1994, 55:423-430.

5I. Galloway SM, Hanrahan V, Dodds KG, Potts MD, Crawford AM, Hill DF: A linkage map of the ovine $\mathbf{X}$ chromosome. Genome Research 1996, 6:667-677.

52. Sonstegard TS, Lopez-Corrales NL, Kappes SM, Stone RT, Ambady S, Ponce de León FA, Beattie CW: An integrated genetic and physical map of the bovine $\mathbf{X}$ chromosome. Mammalian Genome 1997, 8:16-20.

53. Hackett CA, Broadfoot LB: Effects of genotyping errors, missing values and segregation distortion in molecular marker data on the construction of linkage maps. Heredity 2003, 90:33-38.

54. Groenen MA, Cheng HH, Bumstead N, Benkel BF, Briles WE, Burke $T$, Burt DW, Crittenden LB, Dodgson J, Hillel J, Lamont $S$, de Leon AP, Soller M, Takahashi $H$, Vignal A: A consensus linkage map of the chicken genome. Genome Research 2000, 10:137-147.

55. Primmer CR, Raudsepp T, Chowdhary BP, Møller AP, Ellegren H: Low frequency of microsatellites in the avian genome. Genome Research 1997, 7:47|-482.

56. Groenen MA, Crooijmans RP, Veenendaal A, Cheng HH, Siwek M, Poel JJ van der: A comprehensive microsatellite linkage map of the chicken genome. Genomics 1998, 49:265-274.

57. Neff MW, Broman KW, Mellersh CS, Ray K, Acland GM, Aguirre GD, Ziegle JS, Ostrander EA, Rine J: A second-generation genetic linkage map of the domestic dog, Canis familiaris. Genetics | 999, I 5 |:803-820.

58. Kayang BB, Vignal A, Inoue-Murayama M, Miwa M, Monvoisin JL, Ito $S$, Minvielle F: A first-generation microsatellite linkage map of the Japanese quail. Animal Genetics 2004, 35:195-200.

59. May B, Johnson KR: Composition linkage map of salmonid fishes (Salvelinus, Salmo and Oncorhynchus). In Genetic Maps: Locus Maps of Complex Genomes Edited by: O'Brien SJ. New York: Cold Spring Harbor; 1990:15I-159.
60. Young WP, Wheeler PA, Coryell VH, Keim P, Thorgaard GH: A detailed linkage map of rainbow trout produced using double haploids. Genetics 1998, 148:839-850.

61. Sonstegard TS, Barendse W, Bennett GL, Brockmann GA, Davis S, Droegemuller C, Kalm E, Kappes SM, Kühn C, Li Y, Schwerin M, Taylor J, Thomsen H, van Tassell CP, Yeh CC: Consensus and comprehensive linkage maps of the bovine sex chromosomes. Animal Genetics 2001, 32:105-121.

62. Maddox JF, Davies KP, Crawford AM, Hulme DJ, Vaiman D, Cribiu EP, Freking BA, Beh KJ, Cockett NE, Kang N, Riffkin CD, Drinkwater R, Moore SS, Dodds KG, Lumsden JM, van Stijn TC, Phua SH, Adelson DL, Burkin HR, Broom JE, Buitkamp J, Cambridge L, Cushwa WT, Gerard E, Galloway SM, Harrison B, Hawken RJ, Hiendleder S, Henry HM, Medrano JF, Paterson KA, Schibler L, Stone RT, van Hest B: An enhanced linkage map of the sheep genome comprising more than 1000 loci. Genome Research 200I, I I:1275-1289.

63. Hubert S, Hedgecock D: Linkage Maps of Microsatellite DNA Markers for the Pacific Oyster Crassostrea gigas. Genetics 2004, 168:35I-362.

64. Matise TC, Chen F, Chen W, De La Vega FM, Hansen M, He C, Hyland FC, Kennedy GC, Kong X, Murray SS, Ziegle JS, Stewart WC, Buyske S: A second-generation combined linkage physical map of the human genome. Genome Research 2007 17:1783-1786.

65. Handley LJ, Ceplitis H, Ellegren H: Evolutionary strata on the chicken $\mathbf{Z}$ chromosome: implication for sex chromosome evolution. Genetics 2004, 167:367-376.

66. Sundström $\mathrm{H}$, Webster MT, Ellegren $\mathrm{H}$ : Reduced variation on the chicken Z chromosome. Genetics 2004, 167:377-385.

67. Ellegren $H$, Hultin-Rosenberg L, Brunström B, Dencker L, Kultima K, Scholz B: Faced with inequality: chicken do not have a general dosage compensation of sex-linked genes. BMC Biology 2007, 5:40.

68. Storchová R, Divina $P$ : Non-random representation of sexbiased genes on chicken $\mathbf{Z}$ chromosome. Journal of Molecular Evolution 2006, 63:676-68I.

69. Broman KW, Rowe LB, Churchill GA, Paigen K: Crossover interference in the mouse. Genetics 2002, 160:1123-1I31.

70. Montell $\mathrm{H}$, Fridolfsson AK, Ellegren $\mathrm{H}$ : Contrasting levels of nucleotide diversity on the avian $Z$ and $W$ sex chromosomes. Molecular Biology and Evolution 200I, 18:2010-2016.

7I. Lynn A, Kashuk C, Petersen MB, Bailey JA, Cox DR, Antonarakis SE, Chakravarti A: Patterns of meiotic recombination on the long arm of human chromosome 21. Genome Research 2000, 10:1319-1332.

72. Solignac M, Mougel F, Vautrin D, Monnerot M, Cornuet JM: A thirdgeneration microsatellite-based linkage map of the honey bee, Apis mellifera, and its comparison with the sequencebased physical map. Genome Biology 2007, 8:R66.

73. Zenger KR, McKenzie LM, Cooper DW: The first comprehensive genetic map of a marsupial: the tammar wallaby (Macropus eugenii). Genetics 2002, 162:321-330.

74. Samollow PB, Kammerer CM, Mahaney SM, Schneider JL, Westenberger SJ, VandeBerg JL, Robinson ES: First-generation linkage map of the gray, short-tailed opossum, Monodelphis domestica, reveals genome-wide reduction in female recombination rates. Genetics 2004, 166:307-329.

75. Kai W, Kikuchi K, Fujita M, Suetake H, Fujiwara A, Yoshiura Y, Ototake M, Venkatesh B, Miyaki K, Suzuki Y: A genetic map for the tiger pufferfish, Takifugu rubripes. Genetics 2005, 171:227-238.

76. Bouza C, Hermida M, Pardo BG, Fernández C, Fortes GG, Castro J, Sánchez L, Presa P, Pérez M, Sanjuán A, de Carlos A, Alvarez-Dios JA, Ezcurra S, Cal RM, Piferrer F, Martínez P: A microsatellite genetic map of the turbot (Scophthalmus maximus). Genetics 2007, I 77:2457-2467.

77. Sekino M, Hara M: Linkage maps for the Pacific Abalone (Genus haliotis) based on microsatellite DNA markers. Genetics 2007, I75:945-958.

78. Archibald AL, Haley CS, Brown JF, Couperwhite S, McQueen HA, Nicholson D, Coppieters W, Weghe A Van de, Stratil A, Winterø AK, et al:: The PiGMap consortium linkage map of the pig (Sus scrofa). Mammalian Genome 1995, 6:157-175.

79. Kappes SM, Keele JW, Stone RT, McGraw RA, Sonstegard TS, Smith TP, Lopez-Corrales NL, Beattie CW: A second-generation linkage map of the bovine genome. Genome Research 1997 7:235-249. 
80. Dracopoli NC, O'Connell P, Elsner TI, Lalouel JM, White RL, Buetow $\mathrm{KH}$, Nishimura DY, Murray JC, Helms C, Mishra SK, et al.: The CEPH consortium linkage map of human chromosome I. Genomics 1991, 9:686-700.

8I. Stauss M, Tomiuk J, Segelbacher G, Driesel S, Fietz J, Bachmann L, Kömpf J: Sex-specific recombination rates in Parus major and P. caeruleus, an exception to Huxley's rule. Hereditas 2003, 139:199-205.

82. Haldane JBS: Sex ratio and unisexual sterility in hybrid animals. Journal of Genetics 1922, 12:101-109.

83. Trivers $R$ : Sex differences in rates of recombination and sexual selection. In The Evolution of Sex Edited by: Michob R, Levin B. Sunderland: Sinauer Associates; 1988:270-286.

84. Sheldon BC, Merilä J, Qvarnström A, Ellegren H: Female genetic benefit from extra-pair copulation predicted by relative size of male secondary sexual character. Proceedings of the Royal Society B: Biological Sciences 1997, 264:297-302.

85. Houtman AM: Female zebra finches choose extra-pair copulations with genetically attractive males. Proceedings of the Royal Society B: Biological Sciences 1992, 249:3-6.

86. Lenormand T, Dutheil J: Recombination difference between sexes: a role for haploid selection. PLoS Biology 2005, 3:e63.

87. Glazier AM, Nadeau JH, Aitman TJ: Finding genes that underline complex traits. Science 2002, 298:2345-2349.

88. Itoh Y, Arnold AP: Chromosomal polymorphism and comparative painting analysis in the zebra finch. Chromosome Research 2005, 13:47-53.

89. Cramp S, Perrins CM: The Birds of the Western Palearctic Volume VIII. Oxford: Oxford University Press; 1994.

90. Helle P, Lillandt BG: Siberian jay. In The European bird census council atlas of European breeding birds: their distribution and abundance Edited by: Hagemeijer WJM, Blair MJ. London: T \& AD Poyser; 1997:669.

91. Uimaniemi L, Orell M, Mönkkönen M, Huhta E, Jokimäki J, Lumme J: Genetic diversity in the Siberian jay Perisoreus infaustus in fragmented old-growth forests of Fennoscandia. Ecography 2000, 23:669-677.

92. Ekman J, Eggers S, Griesser M: Fighting to stay: the role of sibling rivalry for delayed dispersal. Animal Behaviour 2002, 64:453-459.

93. Lillandt BG, Bensch S, von Schantz T: Parentage determination in kin-structured populations: microsatellite analyses in the Siberian jay Perisoreus infaustus during a 25 -year population study. Avian Science 200I, I:3-14.

94. Derjusheva S, Kurganova A, Habermann F, Gaginskaya E: High chromosome conservation detected by comparative chromosome painting in chicken, pigeon and passerine birds. Chromosome Research 2004, I 2:715-723.

95. Pigozzi MI, Solari AJ: Germ cell restriction and regular transmission of an accessory chromosome that mimics a sex body in the zebra finch, Taeniopygia guttata. Chromosome Research 1998, 6:105-113.

96. Sundström $\mathrm{H}$, Webster MT, Ellegren $\mathrm{H}$ : Is the rate of insertion and deletion mutation male biased?: Molecular evolutionary analysis of avian and primate sex chromosome sequences. Genetics 2003, 164:259-268.

97. Lillandt BG: Lavskrikans (Perisoreus infaustus) populationsutveckling inom ett sammanhängande skogsområde $i$ Sydösterbotten 1974-1992. MSc Thesis, University of Helsinki 1993.

98. Griesser M: Nepotistic vigilance behaviour of Siberian jay parents. Behavioral Ecology 2003, 14:246-250.

99. Green P, Falls K, Crooks S: Documentation for CRI-MAP version 2.4 St. Louis: Washington University School of Medicine; 1990.

100. Nei M: Molecular Evolutionary Genetics New York: Columbia University Press; 1987.

101. Park SDE: Trypanotolerance in West African Cattle and the Population Genetic Effects of Selection. In PhD thesis University of Dublin; 200I.

102. Voorrips RE: MapChart: software for the graphical presentation of linkage maps and QTLs. Journal of Heredity 2002, 93:77-78.
Publish with Biomed Central and every scientist can read your work free of charge

"BioMed Central will be the most significant development for disseminating the results of biomedical research in our lifetime. "

Sir Paul Nurse, Cancer Research UK

Your research papers will be:

- available free of charge to the entire biomedical community

- peer reviewed and published immediately upon acceptance

- cited in PubMed and archived on PubMed Central

- yours - you keep the copyright

Submit your manuscript here:

http://www.biomedcentral.com/info/publishing_adv.asp
BioMedcentral 